\title{
Constructive and Spoon-Feeding Approaches in Teaching Mathematical Expressions: Their Effect to Academic Performance
}

\author{
Elymar A. Pascual
}

Department of Education, Nagcarlan, Laguna, Philippines, 4002

elymarpascual@ rocketmail.com

\begin{abstract}
This study was intended to find the effect of teaching approaches to the performance of the students in Mathematics. Two teaching approaches which are prevalent in Mathematics are considered: constructive approach and spoon-feeding approach. The Union College School of Integrated Preparatory Studies. Thirtytwo out of sixty-five students from the two sections of fourth year high school participated in this study. They were grouped into two (each consisting of 16 students) in such a way that each group equally represents above average and average students. Raised at the beginning of this study were three concerns: the present status of the constructive and spoon-feeding approach as reflected in the teacher-writer, the Mathematical performance of the students after the application of constructive and spoon-feeding approach, and the significant difference between the performance of the group who have undergone constructive approach and the group who have undergone spoon-feeding approach. The concepts regarding the number " 1 " were used as topics in eliciting Mathematical performance from the students. These concepts/expressions are the following: $\mathrm{a}^{0}=1$ (Exponential Function), $0 !=1$ (Factorial) and $0.999 \ldots=1$ (Repeating Decimal). First, the students were made to evaluate the teaching approach of the writer using a survey sheet that contains characteristics of teacher using constructive and spoon-feeding approach. Simple mean was used to analyze which of these two approaches is more often used by the teacher. Second, the constructive approach in teaching was applied to the first group to deliver a series of teachings involving number "1", while the spoon-feeding approach was applied to the second group, in which, after each teaching session, a short quiz was conducted. The total of the three quizzes was computed for each student. Simple mean was also used to find out the average performance of students who have undergone constructive approach and average performance of students who have undergone spoon-feeding approach. Lastly, the significant difference of the total scores in constructive teaching approach and the total scores in spoon-feeding approach was observed using the t-test for two sample mean. It was found out that the teacher-writer was most of the time using the constructive approach based on the average rate of 4.31 which was given by the students (from the scale of $1-5$ with 5 being the highest). The average performance of the students using the constructive approach is 24.44 (equal to $90 \%$ ) from the total of 30-item quiz, while an average of 17.06 (equal to 78\%) for the spoon-feeding approach. The Two Sample Mean Test with .05 level of significance revealed that the tabular value 2.042 is less than the computed value 5.45. Thus, a conclusion that there is a significant difference in the students' performance using the two approaches was considered.
\end{abstract}

Key words: constructive; spoon-feeding; academic performance

\section{Introduction}

"Life is good for only two things: discovering mathematics and teaching mathematics,"

Siméon-Denis Poisson (1781 - 1840)

In Poisson's principle, it can be seen how knowledge of Mathematics has been transferred from generation to generation, and that is by one's discovery and presenting that discovery to the viewing public. Much like what teachers do - discovering knowledge and being able to transfer it to the students using constructive or spoon-feeding approach. 
But, is the transfer of Mathematics' concept been effective these recent years? An Amsterdam-based International Association for the Evaluation of Educational Achievement has been conducting a study that provided information about participating countries' progress or decline in achievement through examinations given every four years since 1995. They published the result as Trends in International Mathematics and Science Study (TIMSS). The Department of Science and Technology (DOST) revealed in the issue of the Philippine Star dated September 15, 2005, that "Filipinos placed 41st and 42nd in the mathematics and science examinations taken by high school students in 45 countries in 2003. Worst, the performance of elementary students in both mathematics and sciences ranked 23rd from among the 25 participating countries." It's degrading and depressing to know that Filipino students performed dismally compared with students in other countries.

Going down into a classroom level, the teaching approach and teachers attitude in teaching Mathematics are important considerations towards students' understanding of the subject matter. Consider this declaration of a high school student regarding Mathematics when he was in elementary, "I clearly remember the day I stopped loving math. I was in the fourth grade and we were doing division. The task was to write and solve division drills. I still remember writing $4 / 0=0$. My teacher crossed out my drill, saying: "This one is wrong". When I asked: "But why? It is 0", she responded: "This one has no answer. It"s a rule. You have to remember it."... I still feel the anger.... At that moment, I started hating math. I realized, for the first time, that math is about memorizing rules that don't make sense." (Tirosh, 2004)

Mathematics teachers tend to assume that if they only present mathematics "as it is", then the students will make an effort to understand mathematical objects and mathematical procedures. Even if the truth is much more complex, there are good reasons to defend this approach as the only available option given the constraints on the teacher. However, it is only effective provided the students start out in a position from which it is possible to be pulled in the desired direction. Sad to say, not all students are in that position to make an effort to understand mathematics the way mathematicians accept and understand it. For this reason, it is good to consider the teacher's approach in teaching Mathematics.

\subsection{Background of the Study}

Teaching approach denotes the nature of the method or technique to be utilized. It indicates how a lesson is to be developed.

Several teaching approaches are now being utilized inside the classroom. The conceptual approach is the process of deriving ideas, rules, concepts, principles or generalization from a given set of related facts. It uses deductive method. Process approach is the teaching of how to acquire skills. It utilizes the principle of learning by doing. Inquiry approach is the search for truth, information or knowledge. It pertains to research and investigation and to seeking information by asking questions. The discovery approach stresses the learning of concepts, theories, principles and contents through discovery rather that rote memorization. It is effective in teaching Science. On the other hand, the communicative approach is effective in teaching oral communication.

The most commonly used approaches in Mathematics nowadays are constructive approach and spoon-feeding approach. While the constructive approach focuses on the experience, observation and input of the students through the guidance of the teacher, the spoon-feeding approach rests solely on the strength and input of the teacher. These two approaches in Mathematics can be seen as extreme opposite of each other. A teacher in Mathematics cannot use the same approach at the same time. It's either he is using the constructive or spoon-feeding approach in a particular teaching session. He may be familiar with the two approaches but will contend to use one of the two approaches depending on the situation. If it is needed to cover a wide range of knowledge in a small amount of time, the spoon-feeding approach is usually to be utilized. The classroom in this kind of approach can be seen to be quiet and students are attentive to take down notes. Rote learning and memorization are the main ingredients of the learning process as the teacher skips the part of the lesson that explains the reason or proof of concepts or theorems. Teachers who use the constructive approach, on the other hand, challenge the students to pass the rough roads which mathematicians of the past had also 
experienced. They are made to observe from their immediate surroundings and are likely to debate among themselves the correct, logical arrangement of objects, facts or elements.

Still, the question of effectiveness between the two approaches arises. With all the factors affecting on the choice of use between the two, and all the excuses from the teachers eliminated, the decision on which approach to use is very much in consideration. It is so important to know the effect of using these approaches in the mathematical performance of the students. The best approach to use in discussing theorems in Mathematics should be settled, knowing the fact that Filipinos are far behind other neighboring countries in terms of progress in mathematical ability.

One such institution that provides quality education in the field of Mathematics is Union College of Sta. Cruz, Laguna founded in 1947 by Dr. Enrique C. Sobrepeña. Interview among Math teachers in this school revealed that constructive approach is the best approach to use in Mathematics. Nevertheless, evaluation of what the students learned using constructive and spoon-feeding approaches have not been tested. For this cause, this study was conducted to explore the possibility of effect of teaching approach to student's performance.

\subsection{Statement of the Problem}

The purpose of this study is to find out the effect of constructive and spoon-feeding approaches in teaching mathematical expressions involving number 1 to the performance of $4^{\text {th }}$ year high school students in Union College.

Specifically, it sought to answer the ff. questions:

1.) What is the status of constructive and spoon-feeding approaches in teaching Math?;

2.) What is the level of performance of students in Mathematical expressions using the following approaches:

a.) Constructive

b.) Spoon-feeding?; and

3.) Is there a significant difference in the performance of students being handled by teacher using the two approaches?

\subsection{Significance of the Study}

The school, school officials, teachers and students are the main beneficiaries of this study.

Principals, as active participant in the curriculum development of their school, will find insight in this study especially on the importance of discussing proofs of theorems on Mathematics and other Mathematics related subjects to their students.

Math department heads can give instruction to their subordinates in using the appropriate approach in teaching that will provide or facilitate their students with the formulation of logical proofs of mathematical theorems and equations.

Math teachers can have self-evaluation on their teaching approach, and by discovering the effect of teaching approach to students' performance, they can either change or reinforce their present teaching approach to elicit better result from students' performance. And through the proposed logical proof presented at the end of this study, Math teachers will gain ease in leading the students towards the proof of Mathematical expressions involving number 1.

High school students will gain understanding and interest in dealing with exponents, factorials and repeating decimals. Whatever proposals for improvement and recommendations advanced in this study shall be toward the enhancement of teaching approach, thereby leading to a better learning process.

Readers can also benefit from this study, whether Mathematics or non-Mathematics major, for they will find fresh new way to view Mathematics as something which is interesting to learn for it develops the logical and analytical thinking of an individual. 
Researchers, on the other hand, can cite concepts on teaching approach and can begin having a similar study for other subjects such as Science regarding the effect of different teaching approaches on student's performance.

\subsection{Scope and Limitation}

Only two teaching approaches are under this study - constructive and spoon-feeding approaches. These seem to be opposite of each other. The inquiry and discovery approaches are considered part of constructive approach for their concepts are interrelated.

Three concepts in Mathematics were chosen to determine the effectiveness of constructive and spoon-feeding approaches. The lessons delivered to the students are the following: exponential function, factorial and repeating decimals.

Fourth year high school students from Union College were chosen to be part of the study. They were chosen to evaluate the approach of their math teacher in dealing with Mathematics, and also, to take series of quizzes out of the lesson delivered to them.

\section{Review of Related Literature and Studies}

This chapter presents a review of investigations that have been conducted and reported which are closely related to the present study. The research paradigm illustrates the association of the variables. The research hypothesis and definition of terms are also presented in this chapter.

\subsection{Related Literature}

\section{1.a. Students' Performance}

Performance means something which is carried out or accomplished. It pertains to the knowledge one has acquired or the skill one has developed in the given subject.

In the article written by Griffiths (2000), the author advocated that the teacher's major business is to produce changes in students. The changes brought about are viewed as students' performance and achievement, and this can be seen in the result of test and evaluation.

The abovementioned principle is analogous to the principle in this present study which accepted that students' learning can be measured through evaluation administered to them.

According to Tall (2000), many people react to Math so strongly that their ability to memorize, concentrate and pay attention is effectively inhibited. In this present study, factors which may inhibit students' learning of Math concepts were assumed to be absent, and the aspect tested was the effect of teaching approach to students' performance.

Educational evaluation is similarly concerned with making judgements about student achievement and progress, although the evidence used has not always been the most reliable (Microsoft Encarta, 2005). Recently, the purposes of evaluation have also come to encompass encouraging the process of learning as well as measuring its outcomes - evaluation for learning as well as evaluation of learning. This statement is equal to the concept that evolved in the present study in the sense that it considered evaluation as a routine under ordinary classroom condition intended to measure students' learning.

\section{1.b. Teaching Approach}

The "Scientific American" article introduces and reprints an essay, entitled "Mathematical Creation", written early in the 20th century by the great mathematician Henri Poincaré. It is said there, "And yet those who can follow this reasoning only with difficulty are in the majority; that is undeniable, and will surely not be gainsaid by the experience of secondary-school teachers. (Microsoft Encarta, 2005). This just underlines 
the importance of secondary school teachers, their experience and their approach in teaching Math. Almost all of what is known in this subject came by the teaching of an effective teacher. As Alcock and Simpson (2002) noted, Math cannot be learned directly from the everyday environment, but only indirectly from other mathematicians. This implies that math learning, specifically in its early stages, and for the average student, is very dependent on the teacher and on good teaching. These declarations are related to the present study in such a way that this study treated teaching approach as a way of relaying concepts and theories in Mathematics to the students.

It may be hard to admit that problem-students in Math are partly caused by teacher-factor. The DOST noted that "language barriers (and) comprehension, teacher qualification, class size, instructional materials (and) equipment, school resources and computer use" are the "what-else-is-new problems" cited in the TIMSS results (Crisostomo, 2005). Since teaching approach was not mentioned by DOST as one of the factors producing problem students, this study was designed to explore the possibility of teaching approach being one of the causes of poor student's performance.

\section{1.c. Constructive Approach}

The prominency of constructivist learning approach emerged during the past decades. Among others, those who provided historical precedents for constructivist learning theory were Dewey, Montessori, Piaget, Bruner, and Vygotsky. Constructivism serves as a bridge from education based on behaviorism to education based on cognitive theory.

Fosnot (1996) has provided a recent summary of these theories and describes constructivist- teaching practice as a teaching approach that focuses on the learner's experience. The present study provides description of constructive approach which is parallel to Fosnot's: facilitating the students towards personal encounter and discovery of concepts and theories in Mathematics.

Four assumptions are basic to what we refer as "constructivist learning." (Gagnon and Collay, 2004)

1. Knowledge is physically constructed by learners who are involved in active learning.

2. Knowledge is symbolically constructed by learners who are making their own representations of action;

3. Knowledge is socially constructed by learners who convey their meaning to others;

4. Knowledge is theoretically constructed by learners who try to explain things they don't completely understand.

This fourth assumption leads to the discussion of proofs of theorems in Mathematics. Leading the students towards the proof of theorems or concepts is a distinct characteristic of the constructive approach. How important is the 'proof' when it deals with math? Garnier and Taylor (2003) emphasized this when they said that 'proof' has been and remains one of the concepts that characterizes mathematics. The student's acceptance of the importance of proof comes along with their difficulties in formulating a proof constructively (Keith,2003). In this situation, it can be seen that teachers have an important role in facilitating the students to overcome these difficulties.

The abovementioned literature about Mathematical proof were cited in the sense that in this study, it was also emphasized that teachers using constructive approach delves deeply into the discussion of proofs so that students may clearly understand the concepts in Mathematics.

www.bellsouth.com/education labelled constructive approach as facilitative and reflective.

Furthermore, it enumerated the following descriptions of constructive teaching approach:
a.) Students engaged in authentic tasks;
b.) Student participation is interactive;
c.) Students grouped heterogenously;
d.) Students learn through exploration;
e.) Teacher is facilitator; and
f.) Assessment based on performance of real tasks. 
Huitt (2003) supported these descriptions when he said that the basic premise of constructivism is that an individual learner must actively "build" knowledge and skills and that information exists within these built constructs rather than in the external environment.

The aforementioned literature are important in this study for they give distinct characteristics of constructive approach which served as a basis for defining and describing the said approach.

The constructive approach ensures understanding and teaches independent, productive thinking. In this approach, "students will do the thinking, even though guided by the teacher" (Tagala, 2001). This implies the difficulty that the teacher and students will undergo just like the Mathematicians of the past have undergone. Nevertheless, the present study set aside the diffficulty that the teacher and students will undergo in this approach, but focuses on the effect of using this approach to the performance of students.

\section{1.d. Spoon-Feeding Approach}

If constructive approach encourages students' analytical and logical thinking, spoon-feeding, on the other hand, stifles the development of students' self-initiative and critical thinking. (DeVries, 2005)

Such a traditional method of faulty instruction leads to boredom and parrot-like learning (Lee, 1995), because memorization is stressed while understanding and reasoning are not emphasized. British novelist E.M. Forster (1879-1970) made a comical notion when he said that spoon-feeding in the long run teaches us nothing but the shape of the spoon.

According to McKay and Kember (1997), spoon-feeding leads to regurgitation. They suggested a better diet which can result to a more digestible learning outcomes.

Associated with spoon-feeding is the belief that students can't do something that renders them inability to perform a task of which they are truly capable (Dodd, 1992).

The abovementioned literature enumerates the characteristics of spoon-feeding appoach and its effect to the performance of students. These are important to the present study in coming up with a clear definition of this approach and in creating the teaching approach indicator survey sheet.

Yahoo.com.spoon-feeding compares and contrasts the two approaches in terms of teachers' role, results and disadvantages. In spoon-feeding, the instructor spoon-feeds the students with step-by-step instructions, while in constructive approach, the instructor guides students to search, to explore, to experiment, to discover, to make choices, to draw their own conclusions, to improvise and to create. Students learn to follow instructions faithfully in spoon-feeding approach, while students develop learning skills and an inquisitive mind in constructive approach. Disadvantages of spoon-feeding are: (1) kills independent thinking and (2) prevents more advanced students from choosing their own pace. On the other hand, some students are frustrated when the teacher uses constructive approach. Spoon-feeding approach seems to have an appeal to the short-term memory, while the constructive approach on the long-term memory. The problem in short-term memory is that $80 \%$ of the facts presented can be forgotten within 48 hours and the remaining $20 \%$ can be forgotten within 2 weeks.

These advantages and disadvantages of constructive and spoon-feeding approaches are relevant to the present study. They give clear distinction between the two approaches that makes it probable to create different response and effect to students' learning process.

\subsection{Related Studies}

\section{2.a. Students' Performance}

Students' performance is important to be monitored for 'it appraises students' growth and development (Morales, 1990)." It is not enough that one should understand the basic principles, theories, scientific facts and procedures. Those things that one has learned should be used and applied in a particular trade which would help him solve related problems and discover new techniques or develop new technology. 
School administrators and teachers alike believe that through evaluation and achievement testing, the extent of learning that has taken place and effectiveness of teaching can be gauged (Velasco, 1998).

Mathematics teachers play an important role to their students in developing this logical thinking and in leading them to create Mathematics on their own. This is true from the result of the study made by Acomular (1998). She found out that there is a significant relationship between the level of performance of students in Mathematics and the teacher's proficiency in the area of professional preparation and instructional skills. Just like Acomular's study, this present study also used $4^{\text {th }}$ year h.s. students as the respondents and participants, with the exemption that Acomular focused on teacher's competency level while this present study dealt with teacher's approach in teaching.

The results of the study made by Jaraplasan (1999) supported Acomular by concluding that there is a significant relationship existing between personal teaching characteristics and the pupils' performance in Mathematics. Personal teaching characteristics in her study includes knowledge of the subject matter area and approach in teaching. While Jaraplasan included teaching approach as one aspect that affects students' performance, the present study dug deeper into the significant effect of teaching approach to students' performance.

Neri (1991) concluded in her study that teaching methodology is a factor that influences the pupils' math performance. This is also true in the study made by Pagola (1999). While Neri and Pagola used elementary students as participants, the present study used $4^{\text {th }}$ year h.s. students as repondents and participants. Also, they investigated on the aspect of teaching methodology while the present study concentrated on teaching approach.

\section{2.b. Teaching Approach}

Math anxiety pervades students and this is why teachers always need an effective approach presenting Math lessons. Math anxiety according to Lava (2002) is the panic, helplessness, paralysis and mental disorganization that arise among some people when they are required to solve Mathematical problem. Through reflection on the nature of their own learning experiences in mathematics some, at least, of the teachers recognize possibilities for transforming their own classrooms (Gardiner, 2002) by using a better approach.

Bonto (1991) recommended in her study that every Math teacher should acquire adequate background training and information in teaching approach by attending summer classes and advanced unit in Math. Teachers should be resourceful enough in making teaching aids and devices out of low-cost instructional materials to supplement the inadequacy of textbooks that results to poor Mathematical performance.

The aforesaid studies are related to the present one because all of them considered enhancement of teaching approach as a solution to Math problem- students.

\section{2.c. Constructive Approach}

Two of the beliefs that came up with the study made by Penaso (2000) which are related to the present study are the following: (1) one must always know how he gets the answer to the problem; and (2) math is creative. It is implied that they believe Math should be taught constructively. There is a preconceived notion among students that they should be active doers and participants in the study of Mathematics in order for them to really learn.

Students accept the fact that the teacher's leading for them to discover the proof of math expressions is really important. In the study conducted by Gardiner (2002), if one were to judge on the basis of what the students wrote, then one would conclude that they accepted the central role of proof, and recognized its importance for anyone wishing to study mathematics. The students believe that the teacher should lead them towards the proof of theorems in Mathematics for in doing so, concepts are more retained in their memoy. 
In the study made by Penaso (2000), he recommended that there is a need to implement sound

Mathematics education reforms in both classrooms and Mathematics teacher education programs.

Changes should take place in the teaching and learning environment. Creating a supportive, problem-

solving centered, cooperative learning environment where application projects are incorporated,

Mathematics history integrated, and a variety of assessment techniques employed may be useful.

In the abovementioned studies, recommendation on the approach to use is specifically cited, and that is the constructive approach. This present study will help validate this recommendation through the performance of the students.

\section{2.d. Spoon-feeding Approach}

In the study made by Sfard (2000), it was revealed that students who were unconvinced with certain Mathematical arguments were students who were just spoon-fed and were not helped to discover the concepts by themselves.

Lava (2002) showed the aspect of teacher behavior that had a negative impact on student attitudes and achievement. It included unrealistic expectations (teachers expect students to understand problems on the first occasion that they were explained and refuse to explain the problem a second time) and insensitive and uncaring attitude (some teachers rely heavily on worksheets but do not explain the content). These comprise the characteristics of a teacher that utilizes spoon-feeding approach.

These are related to the present study in such a way that they describe classroom situation led by a teacher using spoon-feeding approach.

\subsection{Hypothesis}

The tentative answer to the problem is:

There is no significant difference in the performance of students using the two approaches.

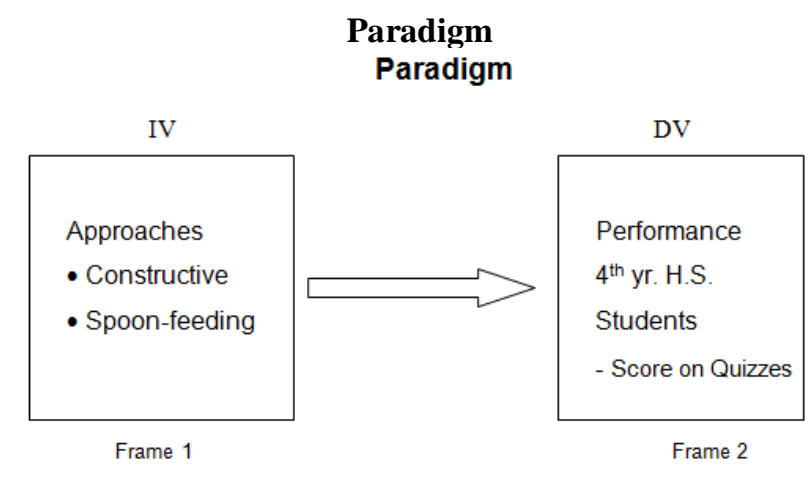

Figure 1. The Research Paradigm Showing the Effect of Teaching Approaches to the Performance of $4^{\text {th }}$ Year High School Students

The structure depicts the effect of the approaches to the performance of $4^{\text {th }}$ year H.S. students in Union College.

Frame 1 consists of the independent variables which contain the approaches as to constructive and spoon-feeding.

Frame 2 consists of the dependent variable which contains the performance of $4^{\text {th }}$ year H.S. students in terms of scores on quizzes. 
2.4. Definition of Terms

The following terms are defined operationally according to the context as they are used in the study.

Constructive. Microsoft Encarta defines constructive as something which is based on what somebody infers from other statements or circumstances. It also means something which is not direct or expressed (New Webster's Dictionary).

As a teaching approach, constructive is defined in this study as the approach utilized by teacher in facilitating students' encounter with new concept, expression or theorem in Mathematics. It involves deductive reasoning and logical sequence of thoughts as guided by the teacher.

Teacher's status of constructive teaching approach is measured in this study in terms of his concern to students' process of learning, use of questions in leading classroom discussion, allowing the students to interrupt the lecture, developing conversation with the students, setting aside time for student's group discussion, provision of time for the students to present and explain their finished work and encouragement for the students' to develop their own notes.

Spoon-feeding. New Lexicon Webster's Dictionary defines spoon-feeding as giving in indulgence all that is needed without having to make any effort to get it. Microsoft Encarta expounds it by stating that spoon-feeding provides somebody with ideas, opinions and judgments to an extent that independent thought becomes unnecessary or impossible.

Spoon-feeding in this study is treated as the teaching approach that caters to the students all the things that they need to know, requiring them to make no effort at all.

Teacher's status of spoon-feeding approach is measured in this study in terms of his textbook presentation of topics, presentation of lots of facts without students' aid, demonstration of all the things he knows about the subject, focusing on good explanation of his own solution, encouragement to the students in memorizing key concepts and theorems, leading the students to focus on what he has provided them and conducting teaching sessions in order to give students a good set of notes.

Performance. According to New Lexicon Webster's Dictionary, this pertains to what is accomplished. Also, it is the effectiveness of the way somebody does his or her work (Microsoft Encarta).

In this study, performance pertains to the students' accomplishments on Math quizzes.

It is measured in this study by computing the total of three quizzes a student got after each lesson on exponential function, factorial and repeating decimal last October 3-7, 2005.

\section{Research Methodology}

This chapter describes the research design, population and sampling, sources of data, research instruments, collection of data and statistical tools use.

\subsection{Research Design}

This study employed the experimental design in research, specifically, a randomized multi-group with a post-test design. Calderon and Gonzales (1993) stated that in this design, there are two or more experimental variables to be tested. So for this study, two groups were formed equal to the number of experimental variables, namely, constructive approach and spoon-feeding approach. The members were assigned randomly to their respective groups. Each teaching approach was applied on the group to which it is assigned. All other variables were kept equal in all the groups. After the experimental period, the same test on the lessons taken by all the groups was given to all of them. The teaching approach assigned to the group with the higher mean score was considered more effective than the teaching approach assigned to the group with lower mean score.

\subsection{Population and Sampling}


The study covered the two sections of fourth year high school in Union College School of Integrated preparatory Studies (UCSIPS), Proverbs and Ezekiel. Proverbs consisted of 32 students while Ezekiel consisted of 33 students. The top 16 students were chosen from each of the two sections. They evaluated their teacher in mathematics (the writer) as to his status in using constructive approach and spoon-feeding approach in teaching Mathematics. Two groups were formed from these 32 students. The two groups, each consisting of 16 students, have equal distribution of average and above average students.

\subsection{Data-Gathering Procedure}

A letter requesting permission to conduct a survey on the teaching approach, series of lessons and evaluations were given to the principal of UCSIPS. Upon her approval, the 32 selected students from the two fourth-year-high-school sections evaluated their teacher in Mathematics using the Teaching Approach Indicator. After this, two groups were formed to undergo series of lessons and evaluations on three topics: exponential function, factorial and repeating decimals. The teacher used constructive approach for the first group and spoon-feeding approach for the second group. Logical proofs were used in the constructive approach for teaching $\mathrm{a}^{0}=1,0 !=1$ and $0.999 \ldots=1$, while no proof for these expressions was presented in spoon-feeding approach. Quiz was given after each lesson, and the total of the three quizzes was computed.

Figure 2 summarizes the procedure done in gathering data for this study.

Figure 2

Summary Flowchart of Data-Gathering Procedure

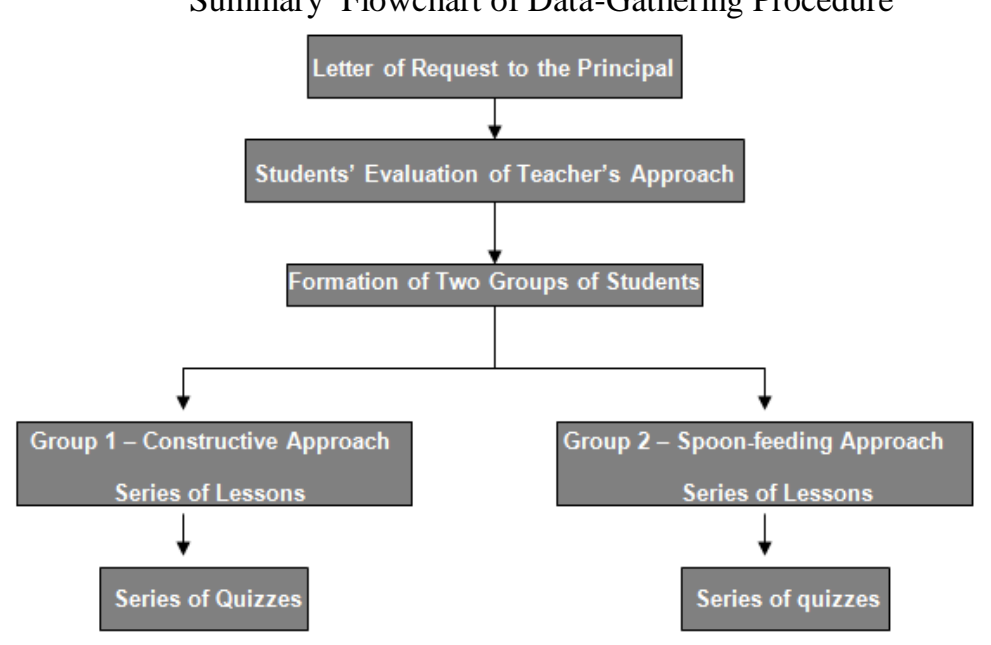

\subsection{Data Gathering Instruments}

The Teaching Approach Indicator Survey Sheet served as the major tool in gathering data for the status of constructive and spoon-feeding approaches.

The items in the Teaching Approach Indicator were primarily based from the following:

a.) suggestions from thesis adviser and principal of Union College (School of Integrated Preparatory Studies);

b.) books and other related studies presented in chapter 2 of this study;

c.) related teaching inventory questionnaire from Union College Center of Excellence; and

d.) researcher's teaching experience and observation. 
The Teaching Approach Indicator was designed according to the sub-problems set in the study. Afterwards, it was checked by the thesis adviser, the principal of Union College and the Dean of Graduate Studies, LSPC, Sta. Cruz, Laguna. The result was a validated Teaching Approach Indicator Survey Sheet containing 14 items which were intended to determine teacher's approach in teaching Mathematics.

Specifically, it inquires about the teacher's concern for students' learning, utilization of questions in teaching, allowance for interruption, student-teacher conversation and interaction, teacher's allowance for students' discussion among themselves, provision for students' presentation of finished work and teacher's attitude towards students' note-taking.

The students were to rate their teacher from 1-5 in these 14 items through the following basis:

1 - rarely or never true for the teacher

2 - sometimes true for the teacher

3 - true for the teacher about half the time

4 - frequently true for the teacher

5 - almost always or always true for the teacher

Items 1, 3, 4, 6, 8, 10 and 13 are characteristics of constructive approach, while items 2, 5, 7, 9, 11, 12 and 14 are for spoon-feeding approach.

Figure 3 summarizes the processes done to have a validated teaching approach indicator survey sheet.

Figure 3

Summary Flowchart of Validated Teaching Approach Indicator Survey Sheet

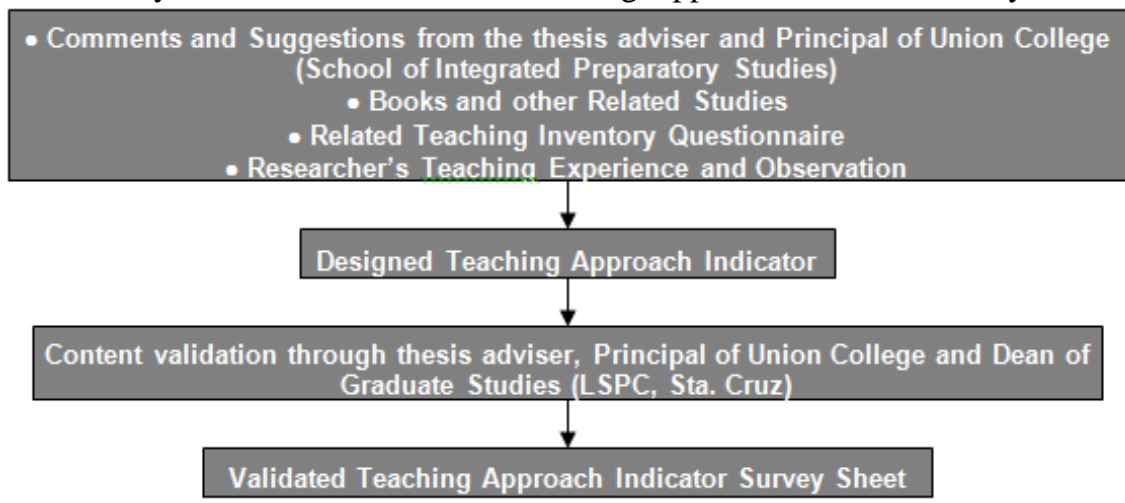

For the students' Mathematical performance, quizzes were designed by first, writing the lesson plans for the three topics to be discussed to the students: exponents, factorials and repeating decimals. For each of the topic, two lesson plans were made: one using the constructive approach and one using the spoon-feeding approach. But on the evaluation part, the same quizzes were given to the students for each of the topic. The quizzes made were referred to the thesis adviser and Math teachers of Union College, and the result was a 10item quiz for each of the lessons. Scores of the students from these three quizzes were added and the total for each student ranges from 0 to 30 .

Figure 4 summarizes the processes done to have validated teacher-made quizzes.

Figure 4

Summary Flowchart of Validated Teacher-Made Quizzes 


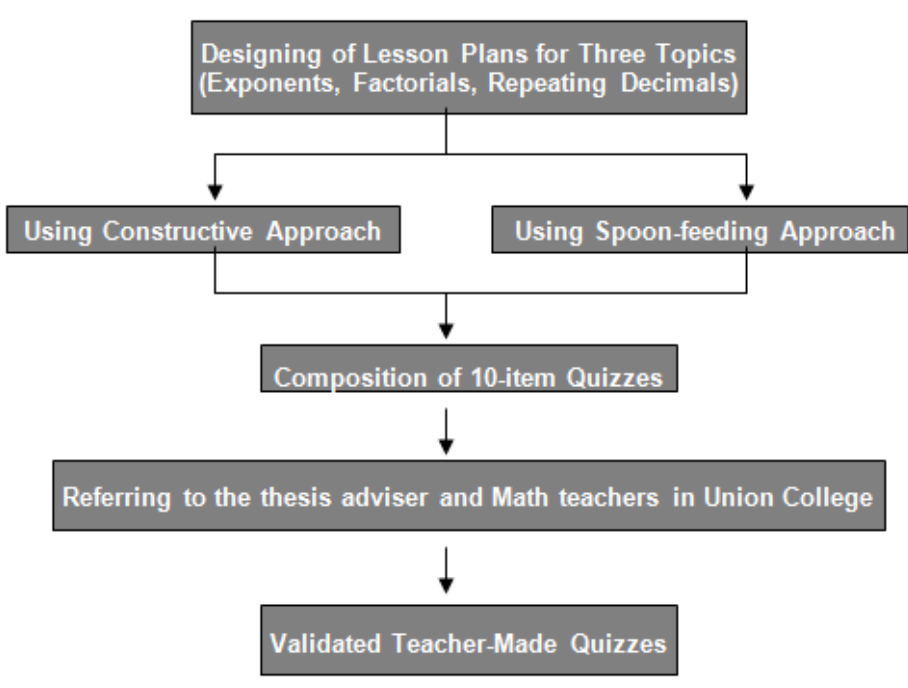

\subsection{Statistical Treatment of Data}

Simple mean $(\mathrm{Mn})$ was used to get the status of constructive teaching and spoon-feeding approaches and the students' Mathematical performance.

$\mathbf{M n}=\Sigma \mathbf{x} / \mathbf{N}$

where $\mathrm{Mn}=$ mean

$$
\begin{aligned}
& \mathrm{X}=\text { rating given by students (or score in quiz) } \\
& \mathrm{N}=\text { no. of items in survey sheet (or no. of students) }
\end{aligned}
$$

On the other hand, the significant difference in the students' performance using the two approaches was measured through Two-Sample Mean Test. This test statistics is useful in comparing two means obtained from two independent or separate samples. It uses the following formula:

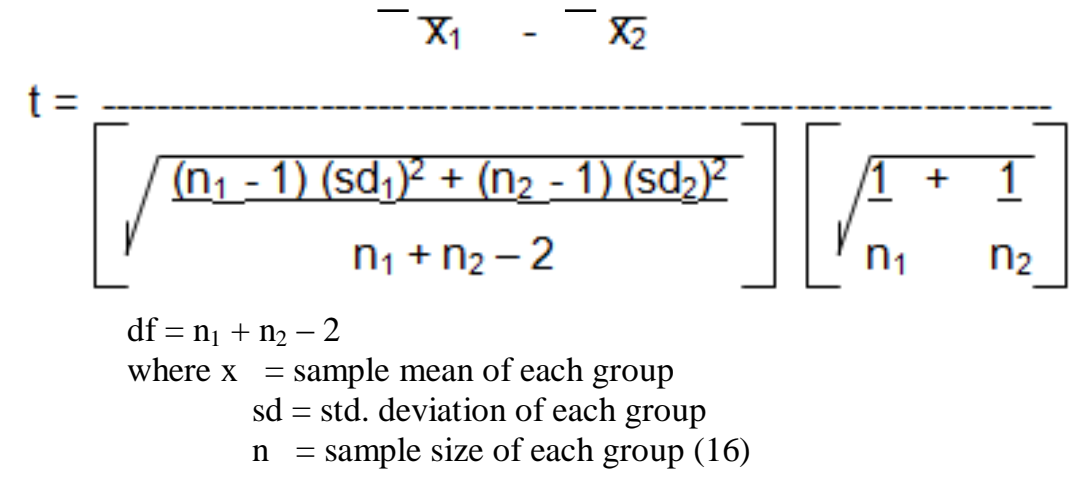

\section{Presentation, Analysis and Interpretation of Data}

This chapter presents in tables and discusses the results of students' evaluation of their teacher's approach in teaching Mathematics. It also presents in figures the scores of the students in their quizzes. Using these tables and figures, analysis and interpretation were made to find the status of teacher's constructive and 
spoon-feeding approaches and the effect of using these approaches to the students' mathematical performance.

The presentation of the findings follows orderly according to how the statement of the problem was presented, namely:

a.) the status of constructive and spoon-feeding approaches in teaching Mathematics;

b.) the level of performance of students in Mathematical expressions involving number 1 using constructive and spoon-feeding approaches; and

c.) the significant difference in the performance of students being handled by teacher using two approaches.

\subsection{Status of Constructive and Spoon-Feeding Approaches in Teaching Math}

Table 1 presents the students' evaluation of teacher's constructive approach as to survey sheet items, the means and their interpretation.

Table 1

Students' Evaluation of Teacher's Constructive Approach

\begin{tabular}{|c|c|c|}
\hline Survey Sheet Items & Mean & Interpretation \\
\hline $\begin{array}{l}\text { Item } 1 \text {. The teacher is concern about both what the } \\
\text { students learn and how they learn. }\end{array}$ & 4.81 & almost always true for the teacher \\
\hline $\begin{array}{l}\text { Item } 3 . \text { The teacher leads the students towards the } \\
\text { reason behind concepts or theorems through series } \\
\text { of questions. }\end{array}$ & 4.56 & almost always true for the teacher \\
\hline $\begin{array}{l}\text { Item } 4 \text {. The teacher allows the students to interrupt the } \\
\text { lecture if they have a relevant question. }\end{array}$ & 4.09 & frequently true for the teacher \\
\hline $\begin{array}{l}\text { Item } 6 . \text { The teacher tries to develop a conversation with } \\
\text { the students about the topics they are studying. }\end{array}$ & 4.50 & frequently true for the teacher \\
\hline $\begin{array}{l}\text { Item } 8 \text {. The teacher sets aside time for the students to } \\
\text { discuss, among themselves, key concepts and ideas } \\
\text { in this subject. }\end{array}$ & 3.94 & frequently true for the teacher \\
\hline $\begin{array}{l}\text { Item 10. The teacher provides time for the students to } \\
\text { present and explain their finished work. }\end{array}$ & 4.56 & almost always true for the teacher \\
\hline $\begin{array}{l}\text { Item } 13 . \text { The teacher treats it better for students in this } \\
\text { subject to generate their own notes rather than copy } \\
\text { teacher's note. }\end{array}$ & 3.72 & frequently true for the teacher \\
\hline Overall Mean Rate & 4.31 & frequently true for the teacher \\
\hline
\end{tabular}

Legend :

$4.51-5.00$ - almost always or always true for the teacher

$3.51-4.50$ - frequently true for the teacher

$2.51-3.50$ - true for the teacher about half the time

$1.51-2.50$ - sometimes true for the teacher

$1.00-1.50$ - rarely or never true for the teacher

As indicated in the results, the overall mean rate given by the students to their Math teacher as to his constructive approach is 4.31 which is interpreted as "frequently true for the teacher." This implies that the teacher allows the students to have active participation in the teaching and learning process and that he welcomes the input of the students as part of the process towards the development of the subject matter.

Table 2 presents the students' evaluation of teacher's spoon-feeding approach as to survey sheet items, the means and their interpretation. 
Table 2

Students' Evaluation of Teacher's Spoon-Feeding Approach

\begin{tabular}{|c|c|c|}
\hline \multicolumn{1}{|c|}{ Survey Sheet Items } & Mean & Interpretation \\
\hline $\begin{array}{c}\text { Item 2. The teacher presents material about the subject } \\
\text { matter as it is presented in the textbook. }\end{array}$ & 2.03 & sometimes true for the teacher \\
\hline $\begin{array}{l}\text { Item 5. The teacher presents a lot of facts to students so } \\
\text { that they know what they have to learn for this } \\
\text { subject, making the students to exert no effort at all. }\end{array}$ & 2.59 & true about half the time \\
\hline $\begin{array}{l}\text { Item 7. The teacher focuses on the good presentation of } \\
\text { his solution. }\end{array}$ & 3.31 & true about half the time \\
\hline $\begin{array}{l}\text { Item 9. The teacher focuses on delivering to the students } \\
\text { what he knows about the subject matter. }\end{array}$ & 3.69 & frequently true for the teacher \\
\hline $\begin{array}{l}\text { Item 11. The teacher encourages the students to } \\
\text { memorize concepts and theorems he has presented } \\
\text { to them. }\end{array}$ & 2.16 & sometimes true for the teacher \\
\hline $\begin{array}{l}\text { Item 12. The teacher leads the students to focus their } \\
\text { study on what he has provided them. }\end{array}$ & 4.13 & frequently true for the teacher \\
\hline $\begin{array}{c}\text { Item 14. The teacher shows that the reason for } \\
\text { conducting teaching sessions in this subject is to } \\
\text { give students a good set of notes. }\end{array}$ & 2.44 & sometimes true for the teacher \\
\hline Overall Mean Rate & $\mathbf{2 . 9 1}$ & true about half the time \\
\hline
\end{tabular}

Legend :

$4.51-5.00$ - almost always or always true for the teacher

$3.51-4.50$ - frequently true for the teacher

$2.51-3.50$ - true for the teacher about half the time

$1.51-2.50$ - sometimes true for the teacher

$1.00-1.50$ - rarely or never true for the teacher

As shown by the results, the students gave their Math teacher an overall mean rate of 2.91 which is interpreted as "true for the teacher about half the time." This implies that the teacher still uses the spoonfeeding approach while having a high mean rate for constructive approach. The teacher can be seen delivering to the students what he knows about the subject matter and leading the students to focus their study on what he has provided them. This can be true depending on the difficulty of the subject matter or the level of understanding of the students.

Table 3 presents the comparative evaluation of the students to their teacher in his constructive and spoon-feeding approaches.

Table 3

Comparative Evaluation Between the Two Approaches

\begin{tabular}{|c|c|}
\hline Approach & Overall Mean Rate \\
\hline Constructive & 4.31 \\
\hline Spoon-feeding & 2.91 \\
\hline
\end{tabular}

A noticeable difference of 1.40 can be seen between the overall mean rate of 4.31 for constructive approach and the overall mean rate of 2.91 for spoon-feeding approach. Since the average on constructive approach is greater than the average on spoon-feeding approach, the teacher can be deemed utilizing the constructive teaching approach more often than the spoon-feeding approach. This implies that the teacher is concerned both on what the students learn and how they learn. He leads the students towards the reason behind concepts or theorems through series of questions and allows the students to interrupt the lecture if they 
have a relevant question. He can be seen trying to develop a conversation with the students about the topics they are studying and setting aside time for the students to discuss, among themselves, key concepts and ideas in this subject. With regards to taking down notes, the teacher treats it better for students to generate their own notes rather than copy his note.

\subsection{Performance of Students}

Figure 5 shows the students' performance in the quizzes given to them after the teaching sessions using constructive approach.

Figure 5

Students’ Performance Using Constructive Approach

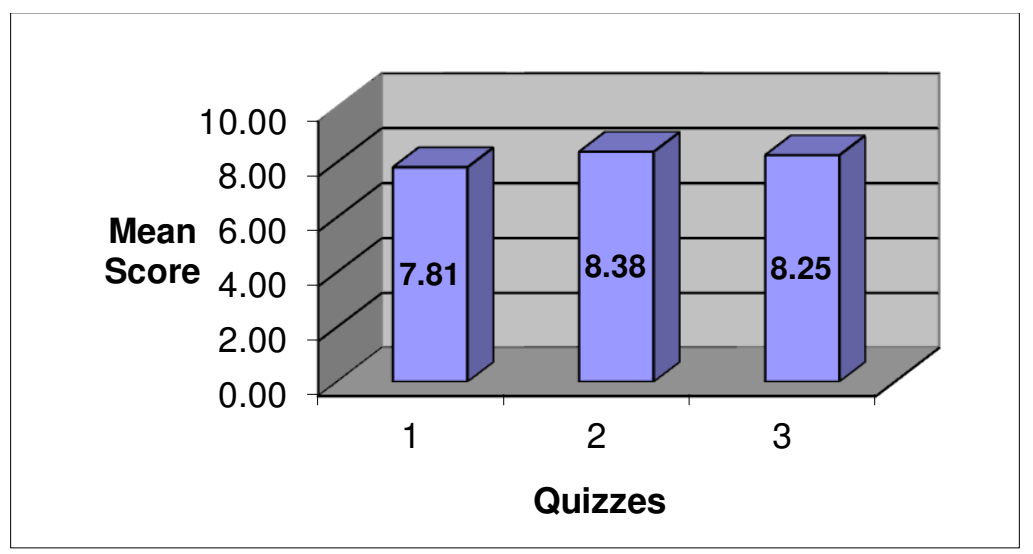

Total Mean Score: $24.44=90 \%$

As indicated in the results, 16 students got a mean score of 7.81 on the first quiz, 8.38 on the second quiz and 8.25 on the third quiz. The total mean score is 24.44 which is equivalent to $90 \%$ using the Union College Transmutation Table (Appendix H). Students got high equivalent scores when the teacher used constructive teaching approach. These imply that the constructive approach instills a teaching process that is clearly understood by the students. Because students did the thinking even though guided by the teacher (Tagala, 2001), this approach ensures understanding and teaches independent, productive thinking resulting to students' good Mathematical performance.

Figure 6 shows the students' performance in the quizzes given to them after the teaching sessions using spoon-feeding approach.

Figure 6

Students' Performance Using Spoon-Feeding Approach

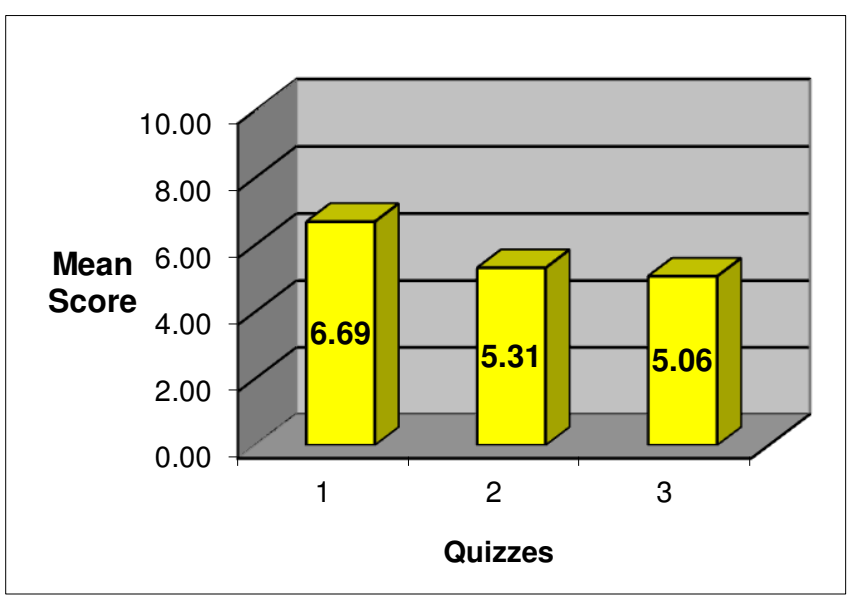


Total Mean Score: $\mathbf{1 7 . 0 6}=\mathbf{7 8 \%}$

As shown by the results, 16 students got a mean score of 6.69 on the first quiz, 5.31 on the second quiz and 5.06 on the third quiz. The total mean score is 17.06 which is equivalent to $78 \%$ using the Union College Transmutation Table (Appendix H). Students got considerably low equivalent scores when the teacher used the spoon-feeding approach. These imply that the spoon-feeding approach instills a teaching process that is vaguely understood by the students. This supports the result of the study made by McKay and Kember (1997) that spoon-feeding leads to regurgitation (act of flowing out or being ejected) and thereby producing poor students' Mathematical performance.

Figure 7 shows the comparative mean performances of the students handled by the teacher using two different approaches.

Figure 7

Students' Comparative Performance

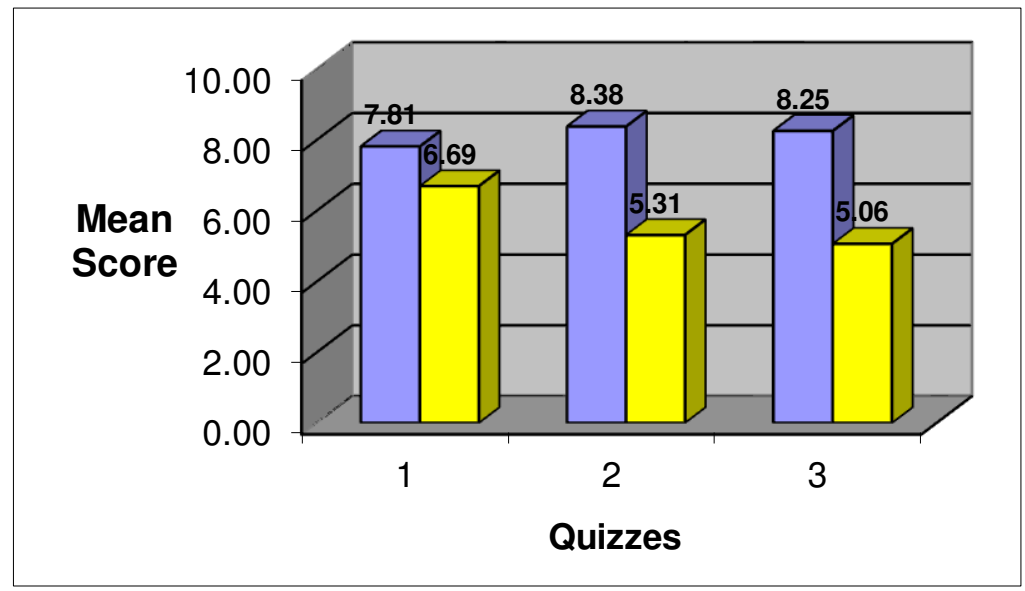

Legend: Mean Scores in Constructive Approach

Mean Scores in Spoon-Feeding Approach

\begin{abstract}
As evidenced by the results, the mean score on first quiz using constructive approach is higher than the mean score on first quiz using spoon-feeding approach by 1.12 points. On the second quiz, mean score on constructive approach is higher than spoon-feeding approach by 3.07 points. On the third quiz, it is still higher by 3.19 points. These imply that students perform better under constructive teaching approach than spoon-feeding approach. Spoon-feeding approach seems to have an appeal to the short-term memory, while the constructive approach on the long-term memory (yahoo.com.spoon-feeding). Also, associated with spoon-feeding is the belief that students can't do something that renders them inability to perform a task of which they are truly capable (Dodd, 1992).
\end{abstract}

\title{
4.3. Effect of Approach to Students' Performance
}

The test of significance between the means of constructive and spoon-feeding approaches is presented in the table. 
Table 4

Test of Significant Difference Between Scores in Constructive Approach and Spoon-Feeding Approach

\begin{tabular}{|c|c|c|c|c|c|}
\hline Approaches & Mean & Difference & $\begin{array}{c}\mathrm{t}- \\
\text { tabular }\end{array}$ & $\mathrm{t}$-computed & interpretation \\
\hline Constructive & 24.44 & & & & \\
\hline Spoon-feeding & 17.06 & 7.38 & 2.042 & 5.45 & Significant \\
\hline
\end{tabular}

\subsection{5 level of significance at $30 \mathrm{df}$}

The data indicate that there is a significant difference between the mean score of the students being handled by a teacher using constructive approach and the mean score of the students being handled by the teacher using spoon-feeding approach since the computed t-value $=5.45$ is greater than the tabular $\mathrm{t}$-value $=$ 2.042. These findings are implications that the students taught by constructive approach learned and achieved mathematical skills better than students taught by spoon-feeding approach as evidenced by big difference of 7.38 in mean scores of 24.44 and 17.06. Constructive approach in teaching elicits better response and performance from students, while spoon-feeding approach hinders students from really learning and understanding the concepts in Mathematics. This supports the result of the study made by Jaraplasan (1998) that that there is a significant relationship between the level of performance of students in Mathematics and the teacher's proficiency in the area of preparation and instructional skills.

\section{Summary, Conclusion and Recommendations}

This chapter summarizes the findings of the study and presents the conclusions as well as the corresponding recommendations.

\subsection{Summary}

Thirty-two fourth year students were chosen to participate in this study. These students came from the two sections of fourth year high school of Union College School of Integrated Preparatory Studies. They were randomly selected to form two groups who have undergone constructive approach and spoon-feeding approach, each group consisting of 16 students.

At the beginning of the study the following questions were raised:

1.) What is the status of constructive and spoon-feeding approaches in teaching Math? ; approaches:

2.) What is the level of performance of students in Mathematical expressions using the following

a.) Constructive

b.) Spoon-feeding?; and

3.) Is there a significant difference in the performance of students being handled by teacher using two approaches?

\subsection{Findings}

The treatment of data revealed the following significant findings:

1.) The average rating for the constructive approach is 4.31 , while the average rating for spoonfeeding approach is 2.91 in the scale of 1 to 5 .

2.) In constructive teaching approach, the students got an overall mean score of 24.44 from the total of 30-item quiz. Through the transmutation table which is now used at Union College, this is equivalent to 
$90 \%$. On the other hand, the students got an overall mean score of 17.06 in spoon-feeding approach. This is equivalent to $78 \%$; and

3.) The computed $t$-value $=5.45$ is greater than the tabular $t$-value $=2.042$ at 0.05 significance level. The null hypothesis is rejected.

\subsection{Conclusion}

Based on the findings of the study, the following are concluded:

1.) The teacher evaluated utilizes constructive approach in teaching Mathematics more often than spoon-feeding approach;

2.) The students performed better when the teacher used constructive approach than when the teacher used spoon-feeding approach; and

3.) There is a significant difference in the students' performance using constructive teaching approach and spoon-feeding approach.

\subsection{Recommendations}

In the light of the conclusion made in this study, the researcher recommends the following:

1.) School principals and authorities should find ways and means to develop school's Math curriculum in such a way that the constructive teaching approach is more utilized rather than the spoon-feeding approach;

2.) Math department heads should give instruction to their subordinates in using constructive approach in teaching which will encourage students' analytical and logical thinking, and will result to better Mathematical performance;

3.) Math teachers should study and practice using constructive approach in teaching. Attending seminars that emphasize constructive teaching approach should not be missed for teachers' enhancement of the said approach;

4.) Graduate School authorities should emphasize constructive teaching approach for those taking education, major in Mathematics; and

5.) The following logical proofs for Mathematical expressions involving number 1 can be used by Math teachers in classroom presentation and discussion :

a.) $\mathbf{a}^{0}=1$

A. Through the Factor 1

$$
\begin{aligned}
& a^{3}=1 \text { (a) (a) (a) } \\
& a^{2}=1 \text { (a) (a) } \\
& a^{1}=1(a) \\
& a^{0}=1
\end{aligned}
$$

B. By Contradiction

$$
\begin{gathered}
\text { Let } \quad \begin{array}{c}
a^{0} \neq 1 \\
a^{0} a^{n}=a^{0+n}
\end{array} \\
a^{0} a^{n} / a^{n}=a^{n} / a^{n} \\
a^{0}=1 \\
\text { but } a^{0} \neq 1, \text { which is a contradiction. } \\
\text { Therefore, } a^{0} \text { must be equal to } 1 .
\end{gathered}
$$

b.) 0 ! = 1

A. Through the Formula

$$
\begin{aligned}
& \mathrm{n} !=\mathrm{n}(\mathrm{n}-1) ! \\
& 1 !=1(0) ! \\
& 0 !=1
\end{aligned}
$$

B. By Contradiction 
Let's assume that 0 ! does not exist.

But $n !=n(n-1) !$.

If $\mathrm{n}=1$, then 1 ! does not exist also.

If 1 ! does not exist, then 2 ! does not exist also.

If 2 ! does not exist, then 3 ! does not exist also.

In general, we can say that $n$ ! does not exist.

c.) $1=0.999 \ldots$

Therefore,we must accept that 0 ! exist and that is equal to 1 .

A. By Reasoning

$1 / 9=0.111 \ldots$

$2 / 9=0.222 \ldots$

$3 / 9=0.333 \ldots$

$4 / 9=0.444 \ldots$

$5 / 9=0.555 \ldots$

$6 / 9=0.666 \ldots$

$7 / 9=0.777 \ldots$

$8 / 9=0.888 \ldots$

$9 / 9=0.999 \ldots$

Therefore, $1=0.999 \ldots$

\section{B. By Contradiction}

Let $1 \neq 0.999 \ldots$

and it is $0.000 \ldots$

It means there's something that must be added to $0.999 \ldots$ to make it equal to 1 ,

Since nothing is to be added, then $0.999 \ldots=1$.

\section{References}

Acomular, P. U. (1998). "The Mathematical Performance of the $4^{\text {th }}$ Yr. Students and the Competency Level of Mathematics Teachers in Selected Public Secondary Nat'1 H.S. in the Division of Laguna," Unpublished Masteral Thesis, Union College of Laguna

Alcock, L. and Simpson. (2002). Dealing with Categories Mathematically. Baltimore: Penguin Books, Inc.

Bonto, L. D. (1991). "Factors Affecting Math Performance of Upper Elementary Grads in the Central School in Catanduanes," Unpublished Masteral Thesis, Catanduanes State Colleges, Virac, Catanduanes.

Crisostomo, S. (Sept. 15, 2005). "RP Students Fare Poorly in International Exam," The Philippine Star.

DeVries, J. (2005). "My Teaching Philosophy," Mathematics Teacher.

Dodd, A.W. (1992). "Insights from a Math Phobic,” Mathematics Teacher, Vol. 85, Iss. 4, pp. 296-298.

Fosnot, C. (1996). Constructivism: Theory, Perspectives, and Practice. New York: Teachers College Press.

Gagnon, G. W. Jr. and Collay, M. (2004). Constructivist Learning Design. New York: Teachers College Press.

Gardiner, T. (2002). "Conflicts between Mathematics Graduates' Proof Behaviors and their Stated Beliefs about Proof," Unpublished Masteral Thesis, School of Mathematics, University of Birmingham, UK.

Garnier, R. and Taylor, R. (2003). 100\% Mathematical Proof. London: Richmond College London Press.

Griffiths, P. A. (2000). "Mathematics at the Turn of the Millennium," American Mathematical Monthly, Vol. 7, Iss. 1, pp. 1-14.

Huitt, W. (2003). Constructivism: Educational Psychology Interactive. Valdosta, Georgia: Valdosta State University Press.

Jaraplasan, T. E. (1999). "Personal Teaching Characteristics and Pupils' Performance in Mathematics as Basis for Teacher's Development Program," Unpublished Masteral Thesis, Union College of Laguna.

Keith, W. (2003). 8 Students' Difficulties with Proof. New Jersey: Rutgers University Press.

Lava, M. C. (2002). "Effects of Math Anxiety on the Learning Process," Iloilo City.

Lee, Q.N. (1995). Eureka! Thoughts on Math. Pasig: Anvil.

McKay, J. and Kember, D. Higher Education Research \& Development. New Yok: New York Press, 1997.

Morales, Leilani G. (1990). "The Magnetic Model in Teaching Compound Formation: Its Relationship to Students Achievement," Unpublished Masteral Thesis, TUP, Manila.

Neri, E. N.(1991). "Factors that Influence the English and Mathematics Performance of Grade VI Pupils," Unpublished Masteral Thesis, Agusan Institute of Technology, Butuan City.

New Lexicon Webster's Dictionary of the English Language.

Pagola, J. D. (1999). "Factors Associated with the Mathematics Performance on Problem Solving of Grade III Pupils in Selected Schools, Division of Laguna, s.y. 1998-1999," Unpublished Masteral Thesis, Union College of Laguna. 
Penaso, A. M. (2000). "Student Perceptions of Mathematics Myths: Curricular and Instructions Implications," Central Mindanao University.

Sfard, A. (2000). “On Reform Movement and the Limits of Mathematical Discourse," Unpublished Masteral Thesis, Haifa, Israel University.

Suttiprapa, R. (1988). "The Factors Affecting the Choie of Career Among Students in the Lower Secondary Schools in Thailand," Unpublished masteral Thesis, TUP, Manila.

Tall, D. (1996). The Psychology of Advanced Mathematical Thinking. Kluwer: The Netherlands.

Tagala, R. ( $1^{\text {st }}$ Quarter 2001). "Why Teach Mathematics," Intersection, pp. 15-17.

Tirosh, D. (2004). "The Cases of Division by Zero," Dept. of Science Education Journal, Tel-Aiv University, Israel.

Velasco, Cecilia P. (1998). "Effects of Technology-Oriented Modular Instruction in Teaching English: Implication for Curriculum Development," Unpublished Masteral Thesis, TUP, Manila. 